\title{
Gestational diabetes: An overview with attention for developing countries
}

\author{
${ }^{1}$ Schiavone M, ${ }^{2}$ Putoto G, ${ }^{3}$ Laterza F, ${ }^{4}$ Pizzol D \\ ${ }^{1}$ Unit of Neonatology and Intensive Care, General Hospital, University of Bari, Bari, Italy; \\ ${ }^{2}$ Research Section, Doctors with Africa CUAMM, Padova, Italy; \\ ${ }^{3}$ Gynaecology and Obstetrics Unit, General Hospital, University of Bari, Bari, Italy; \\ ${ }^{4}$ Research Section, Doctors with Africa CUAMM, Beira, Mozambique \\ E-mail:d.pizzol@cuamm.org
}

\begin{abstract}
Gestational diabetes mellitus (GDM) is defined as a glucose intolerance that occurs for the first time or it is first identified during pregnancy. The GDM etiology is multifactorial. It has not completely been established yet and several known risk factors may contribute to its onset. To date, there are no shared guidelines on the management and follow-up, especially regarding the lowincome countries. In this paper, we describe the state of art about epidemiology, physiopathology, diagnosis, and management of GDM. Moreover, we focus on the current state in low income countries trying to outline basis for further research.
\end{abstract}

Key words: gestational diabetes mellitus, GDM, management, epidemiology, low-income countries

Diabetes mellitus (DM) is one of the major actual public health issues consisting of chronic hyperglycemia which can damage body organs and systems (Karamanou et al. 2016). Gestational diabetes mellitus (GDM) is a common metabolic complication in pregnancy, defined as a glucose intolerance identifying for the first time during pregnancy (ReyesLopez et al. 2014). GDM reveals usually between 24 and 28 weeks of gestation, without particular symptoms, but it should be screened as early as possible to avoid severe short- and long-term complications for mother, fetus or neonate (Hawryluk et al. 2015). Insulin resistance in peripheral tissues and pancreatic beta-cells inadequacy to secrete insulin represent the double pathways involved in the hyperglycemia. On one side, during normal pregnancy, insulin sensitivity declines, leading to a higher insulin resistance in peripheral tissues, due to placental factors, progesterone and estrogen, having insulin-antagonistic effects (Reyes-Lopez et al. 2014). On the other side, GDM occurs if pancreatic beta-cells are unable to face the increased insulin demand during pregnancy and the elevated glucagon-like peptide 1 (GLP-1) confirms the abnormal insulin secretion (Reyes-Lopez et al. 2014). In a physiological situation, a compensatory increased insulin secretion maintains a normal glucose homeostasis. To date, several pathophysiological mechanisms have been proposed, such as metabolic, inflammatory, autoimmune, and genetic ones. It is likely that it is a multifactorial etiology (Baz et al. 2015; Issat et al. 2015). As diabetes is often asymptomatic in the first stages, the early diagnosis is solely biochemistry, while late untreated stages may include following symptoms: blurred vision, fatigue, frequent bladder, vagina and skin infections, polydipsia, polyuria, nausea and vomiting, and weight loss despite increased appetite (American Diabetes Association 2016). The GDM management includes, other than therapy for diabetic women, also prevention and follows up of all at risk patients, not only during preg- 
nancy, but also in postpartum (Castorino and Jovanovic 2013).

In this article, we review the epidemiology of GDM, the physiopathology and the management of this relevant disease with particular attention to the developing countries.

\section{Epidemiology}

GDM is the most common metabolic disorder of pregnant women with an estimated prevalence ranging from $<1 \%$ to $28 \%$. However, in the countries where universal screening is recommended, the percentage of pregnant women screened ranges from $10 \%$ to $>90 \%$ (Jiwani et al. 2012).The frequency of its occurrence depends, inter alia, on diagnostic methods, ethnicity, and body composition. In fact, many countries do not perform systematic screening for GDM, adopting different guidelines or practices diverge from them. Again, some ethnic groups have long been associated with an increased risk of GDM and its prevalence seems particularly higher among women from South Asia and South East Asia than from Caucasian, African-American and Hispanic communities. In particular, GDM rate ethnicity is 11.9\% for Asian and Pacific Island, 7.6\% for American Indian, 5.6\% for Black American, 8.4\% for Hispanic, 5.4\% for Non-Hispanic White, and 6.6\% for other (Kim et al. 2013). The prevalence of GDM in women who were born in Asian countries varied from $3.0 \%$ to $21.2 \%$. Interestingly, the risk to develop GDM for South-Asian (Indian, Sri Lankan, Pakistani, Fijian Indian) women is higher than the SouthEast Asian (Cambodian, Vietnamese, Laotian, Thai, Filipino, Malaysian) and the East-Asian (Chinese, South Korean, Taiwanese and Japanese) ones (Chu et al. 2009; Yuen and Wong 2015). Among different ethnicities, also mother and child outcomes have important variations. As for perinatal outcomes, newborns from Pacific Islander countries have higher rates of macrosomia, while children with Chinese backgrounds lower adverse outcomes (Yuen and Wong 2015). From a maternal point of view, Asian pregnant women affected by GDM have a higher incidence of postpartum glucose intolerance and development of type 2 DM (Yuen and Wong 2015; Girgis et al. 2012). The "non-Hispanic white" seems to have a lower rate of GDM recurrence (39\%) compared with other ethnic groups (56\%) (Schwartz et al. 1999) while, women from Hispanic or AfricanAmerican backgrounds with GDM have more likely developed hypertension post-partum (Yuen and Wong 2015).

\section{Physiopathology}

In GDM, many biologic and molecular mechanisms of regulating glucose levels are involved. It has been demonstrated that inadequate decrease of the renal threshold for glucose (RTG) that is determined by the nephron's reabsorption capacity, play a role in the development of GDM. In fact, glucose is reabsorbed through sodium glucose transporters in the proximal tubules. However, during pregnancy, the renal glucose reabsorption capacity decreases due to reduced glucose transporter expression leading to lower glucose elimination (Klein et al. 2014). From the molecular point of view, many regulators seem to play a role in the glucose homeostasis and GDM onset. During a normal pregnancy, the balance of T-helper cell activity is strongly shifted toward an anti-inflammatory profile, characterized by Th-2 cytokines, which have a protective role in the fetalmaternal relationship (Abell et al. 2015). Moreover, during pregnancy a fine balance occurs between proand anti-inflammatory cytokines, needed for the normal development (Abell et al. 2015). In particular, GDM seems to be linked to the down-regulation of adiponectin and anti-inflammatory cytokines (e.g. IL-4, IL-10) and up-regulation of adipokines like leptin and pro-inflammatory cytokines, implicated in insulin resistance [e.g. IL-6, TNF- $\alpha$, adipocyte fatty acid-binding protein (AFABP)] (Abell et al. 2015). In Table 1, the main agents, involved in the GDM physiopathology, are reported (Qiu et al. 2004; Lewandowski et al. 2007; Mordwinkin et al. 2013; Lappas 2014; Abell et al. 2015; Iyidir et al. 2015; Pala et al. 2015).

\section{Risk factors}

Many risk factors are involved in the development of GDM. First, mainly woman with previous GDM and/or high prevalence of glucose intolerance in the early postpartum period are at increased risk for its developing (Capula et al. 2014). In fact, it seems that they have high catalase levels, indicating the potential oxidative stress effects on postpartum glycemic status related to glucose intolerance (Roca-Rodriguez et al. 2014). Moreover, women with prior GDM have more frequently glutamic acid decarboxylase (GAD) autoantibodies (Lundberg et al. 2015). Thus, metabolic status can represent a risk factor, in particular, high levels of fasting plasma glucose (FPG), triglyceride, total cholesterol, low density lipoprotein (LDL), fasting insulin (FINS), and homeostasis model assessment of insulin resistance (HOMA-IR) and low levels 
of high density lipoprotein (HDL), are considered independent risk factors for GDM (Shuang and Huixia 2014). Interestingly, low levels of 25-hydroxyvitamin $\mathrm{D}[25(\mathrm{OH}) \mathrm{D}]$ at first trimester is another independent risk factor for developing GDM. It is associated with insulin resistance at second trimester (Lacroix et al. 2014). Growing evidence suggests a role of environmental chemicals, as arsenic, phthalates, bisphenol A, metals $\mathrm{NOx}, \mathrm{SO}_{2}$ and $\mathrm{O}_{3}$ in the development of GDM (Robledo et al. 2015; Shapiro et al. 2015). By contrast, moderate coffee and tea intake may have a protective effect (Hinkle et al. 2015). Women with a history of infertility and polycystic ovary syndrome (PCOS) seem to be more affected by GDM (Ashrafi et al. 2014). Furthermore, the GDM risk is two-fold higher in women undergoing assisted reproductive technology (ART) compared with women who conceived spontaneously. Another important risk factor for GDM is the use of progesterone during pregnancy (Ashrafi et al. 2014). At last, an issue that is still to be clarified is the genetic susceptibility. To date, some studies have shown pathological involvement of single nucleotide polymorphisms (SNPs). In particular, SNP for ENPP1 gene both homozygous for A allele and heterozygous is associated with GDM. Moreover, AA homozygous genotype, associated with age ( $\geq 35$ years) and pre-

Table 1

The main factors involved in GDM physiopathology.

\begin{tabular}{|c|c|}
\hline Name & Description \\
\hline Adiponectin & $\begin{array}{l}\text { Adiponectin is a plasma protein secreted from adipose tissue and it is decreased in obesity. It is an insulin- } \\
\text { sensitizing, anti-inflammatory and anti-atherogenic adipokine that stimulates glucose uptake in skeletal } \\
\text { muscle and reduces hepatic glucose production through AMP-activated protein kinases. Down-regulation } \\
\text { of adiponectin may predict GDM several months before clinical diagnosis, independent of BMI status. Low } \\
\text { levels of adiponectin exacerbates insulin resistance and correlates with } \beta \text { cell dysfunction. }\end{array}$ \\
\hline Adipokine & $\begin{array}{l}\text { Adipokine secretion contributes to glucose homeostasis in pregnancy by direct (insulin secretion regulation } \\
\text { and insulin sensitivity) and indirect (adipogenesis regulation and immune cells chemoattraction) } \\
\text { mechanisms. Adipokine secretion increase insulin resistance. }\end{array}$ \\
\hline $\begin{array}{l}\text { TNF- } \alpha \\
\text { IL-6 }\end{array}$ & $\begin{array}{l}\text { TNF- } \alpha \text { and IL- } 6 \text { are produced by placenta, adipose tissue monocytes and macrophages and lead to insulin } \\
\text { resistance. In GDM, particularly during second and third trimester, oxidative stress and inflammation } \\
\text { induced by hyperglycemia, further increase levels of TNF- } \alpha \text { and IL- } 6 \text {. }\end{array}$ \\
\hline Leptin & $\begin{array}{l}\text { Leptin is a hormone protein released by adipose tissue and suppresses insulin secretion from pancreatic } \\
\text { beta cells. Moreover, leptin is involved in appetite control, body weight and composition and energy } \\
\text { consumption. Increased leptin synthesis in GDM stimulates production of pro-inflammatory cytokines such } \\
\text { as IL- } 6 \text { and TNF- } a \text {, which further enhances leptin production. }\end{array}$ \\
\hline AFABP & $\begin{array}{l}\text { Adipocyte fatty acid-binding protein belongs to the fatty-acid binding proteins family and is highly } \\
\text { expressed in adipocytes, macrophages and endothelial cells. Serum AFABP levels are increased in the third } \\
\text { trimester and result up-regulated in GDM and seems to induce insulin resistance. }\end{array}$ \\
\hline Resistin & $\begin{array}{l}\text { Resistin is a hormone expressed in monocytes and macrophages, and adipocytes. It seems to have a role } \\
\text { in insulin resistance during pregnancy, without a central role in glucose homeostasis and development of } \\
\text { GDM. }\end{array}$ \\
\hline Visfatin & $\begin{array}{l}\text { Visfatin is highly expressed in visceral adipose tissue, promotes adipogenesis and has insulin-mimetic } \\
\text { effects. Visfatin is reported to be both decreased and increased in GDM. }\end{array}$ \\
\hline Fetuin A & $\begin{array}{l}\text { Fetuin } \mathrm{A} \text { is a blood proteins produced by the liver and play a role in the development of insulin resistance } \\
\text { and the metabolic changes in GDM. It is increased during pregnancy and decreased after delivery. }\end{array}$ \\
\hline EPC & $\begin{array}{l}\text { Decreased levels of maternal circulating endothelial progenitor cells increase soluble adhesion molecules } \\
\text { adhesion in maternal blood, decrease expression of superoxide dismutase and increase endothelial nitric } \\
\text { oxide synthase expression in maternal and cord blood leading increased oxidative stress and endothelial } \\
\text { dysfunction women and fetuses. }\end{array}$ \\
\hline Vitamin D & $\begin{array}{l}\text { Low vitamin } \mathrm{D} \text { is implied in the etiology of obesity, insulin resistance and diabetes mellitus probably due to } \\
\text { a chronic low-grade inflammation mechanisms. Vitamin D deficiency is common in pregnancy, and may } \\
\text { contribute to abnormal glycemic control. }\end{array}$ \\
\hline $\begin{array}{l}\text { Reactive } \\
\text { oxygen } \\
\text { species }\end{array}$ & $\begin{array}{l}\text { Oxidative damages cause mitochondrial dysfunction and impair antioxidant mechanisms. Reactive oxygen } \\
\text { species have an important role in pathogenesis of almost all chronic metabolic diseases and in GDM they } \\
\text { lead insulin resistance. }\end{array}$ \\
\hline
\end{tabular}

GDM - gestational diabetes mellitus; BMI - body mass index; TNF- $\alpha$ - tumor necrosis factor- $\alpha$; IL-6 - interleukin-6; AFABP adipocyte fatty acid-binding protein; EPC - endothelial progenitor cells 
gestational high body weight and body mass index (BMI) increased significantly the risk of impaired glucose tolerance and GDM (Tarquini et al. 2015).

\section{Complications}

GDM complications may occur on newborns or mothers. In fact, newborns can be affected by birth defects, impaired intrauterine fetal growth, and higher incidence of premature births and greater percentage of the intrauterine fetus death (Hawryluk et al. 2015). In particular, macrosomia is the main adverse pregnancy outcome due to the fetal hyperinsulinism, developed in response to maternal hyperglycemia. Furthermore, intrauterine exposure to GDM is linked to development of hypertension, obesity, and type $2 \mathrm{DM}$ in children (Blue et al. 2015). On the other side, mothers may face complications in shortor long-term. Short-term, they may show high stress level, low sleep quality, and impaired cognitive functions (Hayase et al. 2014; Keskin et al. 2015). Moreover, they can develop thyroiditis, renal diseases, and type 2 DM (Beharier et al. 2015; Hopmans et al. 2015; Maleki and Tavosi 2015). Long-term effects, instead, are subclinical atherosclerosis, arterial hypertension, and cardiovascular disease (CVD) (Li et al. 2014; Oliveira et al. 2015). The association between GDM and CVD is so strong that in the absence of other recognized cardiovascular risk factors, such as smoking, obesity or chronic hypertension, GDM represents a useful marker of raised CVD risk among women with BMI between 25 and 29 (Fadl et al. 2014).

\section{Diagnosis}

It is well known that early diagnosis is crucial to ensure the most effective treatment and lower consequences for mother and newborn. Identifying pregnant women with risk factors for GDM based on the clinical suspicion is a popular approach. Moreover, pregnant women without known DM should be screened for DM after 24 weeks of gestation, including glucose monitoring and lifestyle educations (Garrison 2015). World Health Organization (WHO) established criteria for the GDM diagnosis and the prevention, but to date, many strategies exist addressed to this issue (Aktun et al. 2015). Different structured checklists to identify risk women have been developed and though their effectiveness has to be still assessed (Fawole et al. 2014). In Sherbrooke, Regional Committee proposed GDM screening during the first trimester for all pregnant women based on a 50 g glucose challenge test (50 g GCT), followed directly by capillary self-monitoring blood glucose (SMBG) at home (Allard et al. 2015). The Societe Francophone du Diabete (SFD) and the College national des Gynecologues et Obstetriciens Français (CNGOF) proposed a selective screening based on risk factors rather than universal screening, measuring fasting blood glucose at the first visit for women with risk factors (Vambergue 2013).

Three methods are commonly used for GDM screening: fasting plasma glucose (FPG), two-step $50 \mathrm{~g}$ glucose challenge test (GCT), and 75 g glucose tolerance test (GTT). Although there is no a common opinion, $75 \mathrm{~g}$ GTT seems to be preferred for GDM screening in the first trimester (Yeral et al. 2014). The International Association of Diabetes in Pregnancy Study Groups (IADPSG) have developed recommendations for the use of a $75 \mathrm{~g}, 2-\mathrm{h}$ GTT, $\geq 1$ elevation diagnosing GDM, with follow thresholds: fasting plasma glucose $\geq 5.1 \mathrm{mmol} / 1$ (92 mg/dl), $1 \mathrm{~h}$ $\geq 10 \mathrm{mmol} / \mathrm{l}(180 \mathrm{mg} / \mathrm{dl})$, and $2 \mathrm{~h} \geq 8.5 \mathrm{mmol} / \mathrm{l}(153$ $\mathrm{mg} / \mathrm{dl}$ ) (Coustan 2014). However, USA, European countries, and Australia have developed their own guidelines based on the maternal risk of subsequent diabetes, on arbitrary statistics, or on non-pregnant women. The International Association of Diabetes and Pregnancy Study Group, for the first time, proposed new diagnostic criteria for gestational diabetes mellitus, based also on perinatal outcome (Houshmand et al. 2013). This topic is still controversial. On one side, some authors suggest to use estimated fetal weight (EFW) from ultrasonography at 18 to 22 weeks, to predict GDM and newborn macrosomia (Liao et al. 2014). On the other side, other authors prompt that EFW at 18 to 22 weeks does not predict the onset of GDM, but large for gestational age (LGA) (Liao et al. 2014).

Other markers are much less used and with poor scientific evidence. For example, the utility of hemoglobin A1c (HbA1c) that is a widely used in diagnosing type $2 \mathrm{DM}$ is not yet established for GDM (Kwon et al. 2015). Interestingly, glycated albumin is not influenced by iron deficiency and therefore, it might be a better indicator of glycemic control in patients with GDM and pregnant women with diabetes mellitus (Hashimoto and Koga 2015). Moreover, highsensitive C-reactive protein (hs-CRP) and maternal serum sex hormone binding globulin (SHBG) are less used but can be important early predictors of GDM as well uric acid, creatinine, and albumin (Maged et al. 2014). Measurement of serum PlGF at 11-14 weeks improves the performance of early screening for GDM (Eleftheriades et al. 2014). Yilmaz and colleagues have suggested also the neutrophil-to-lym- 
phocyte ratio (NLR) as an independent predictor of GDM development (Zhu et al. 2015). Finally, in the next future, miRNA expressed in GDM could serve as earlier predictive markers (Zhu et al. 2015). In particular, Dicer and Drosha are the two major enzymes in the miRNA biogenesis process with evidence of up-regulation in GDM patients (Rahimi et al. 2015).

Management: prevention, therapy and follow-up

\section{Prevention}

GDM prevention is not only crucial for mother and newborn health, but also for reducing the economic burden of this disease (Dall et al. 2014). All health institutions recommend lifestyle interventions that include exercise and healthy diet, both to prevent and manage GDM (Artal 2015). Moderate and controlled physical exercise has a powerful potential to help blood glucose control with benefit in prevention and treatment (Sanabria-Martinez et al. 2015). To date, there are no guidelines available for exercise in GDM. The recommendation of both aerobic and resistance exercises of a moderate intensity, a minimum of three times a week for 30-60 minutes as suggested by some authors (Padayachee and Coombes 2015), is still controversial (Ruchat and Mottola 2013). Although a specific diet does not exist, the conventional diet approach to prevent and fight GDM provides carbohydrate restriction (Hernandez et al. 2014). Interestingly, Mediterranean diet pattern seems to be associated with better glucose tolerance and lower incidence of GDM (Karamanos et al. 2013). Moreover, as short sleep duration and sleep disorders are risk factors for poor glycemia control, educating women on healthy sleep and screening for and treating sleep disorders during pregnancy may have a role in optimizing gestational diabetes prevention (Twedt et al. 2015). In women with a history of GDM or PCOS, in addition to lifestyle, also metformin seems to be highly effective in reducing progression to diabetes due to its metabolic, endocrine, vascular, and antiinflammatory effects (Khattab et al. 2011; Aroda et al. 2015; Poomalar 2015).

\section{Therapy}

The aim of GDM treatment following WHO criteria is to normalize blood glucose level in order to reduce risk of the adverse maternal and neonatal complications, such as cesarean section, polyhydramnios, preterm delivery, neonatal intensive care, and high neonatal weight (Aktun et al. 2015). The first-line therapy is insulin, which is not only safe but also useful to restore placental endothelial function (Sobrevia et al. 2015). In fact, it was demonstrated that in diet-treated GDM, although maternal and newborn glucose levels were normal, fetoplacental vascular dysfunction lasted. In these cases, insulin addiction may restore the normal metabolic condition of the vascular network, promoting the health of the growing fetus, newborn, and mother (Sobrevia et al. 2015). In addition, insulin treatment of mild GDM has been associated with neonatal benefits, while no reduction in childhood obesity or metabolic dysfunction in the offspring has been observed (Landon et al. 2015). The main insulin therapy limitations are hypoglycemia and weight gain (Mirzamoradi et al. 2015). Moreover, it could represent a complicated therapeutic option due to the difficulty in administration with multiple daily injections (Magon and Seshiah 2011). Most insulin analogues (insulin lispro, aspart and detemir) are also considered safe and with comparable results in pregnancy (Simmons 2015). Interestingly, subcutaneous insulin with continuous glucose monitoring system may play a role in women requiring higher dosage (Poomalar and Rangaswany 2013).

Currently, there is growing interest in oral drugs as glyburide (second-generation sulfonylurea) and metformin (biguanide) due to the better patients' adherence and their safety, effectiveness and cheapness (Magon and Seshiah 2011). In particular, metformin seems to be effective and safe for the treatment GDM, particularly for overweight or obese women and patients with PCOS, due to maternal weight lowering, better neonatal outcomes, reduction of early pregnancy loss, and fetal growth restriction (Lautatzis et al. 2013). Interestingly, although there are no guidelines for the continuous use of metformin in pregnancy, teratogenic effects, intra-uterine deaths or developmental delays have been not demonstrated. However, in patients with multiple risk factors for insulin resistance, it is not enough and insulin supplementation is necessary (Lautatzis et al. 2013). Particular attention has to be paid to glyburide and metformin due to their altered pharmacokinetics during pregnancy and their ability to cross the placenta (Ryu et al. 2014). Moreover, metformin seems to be associated with gastrointestinal adverse effects, while glibenclamide is associated with hypoglycemia and weight gain (Simmons 2015).

\section{Follow up}

Women with gestational diabetes mellitus need a continuum care before, during, and after pregnancy 
for optimal management of hyperglycemia, including education and lifestyle modification (Castorino and Jovanovic 2013). Self-monitoring of blood glucose has been found more effective than the clinical glucose blood checking due to its higher ease and frequency (Magon and Seshiah 2011). If GDM is correct and regular, pregnancy can safely get to 39 weeks, while, if glycemic control is poor or there are others indicators for delivery, such as maternal medical conditions, obstetric complications or major congenital anomalies, cesarean delivery should be considered preferably in women with an estimated fetal weight greater than $4500 \mathrm{~g}$ (Garrison 2015). Since women with GDM have a 7-fold higher risk of developing diabetes, they should be screened 6 to 12 weeks postpartum and every 3 years thereafter (Olesen et al. 2014). However, follow-up rates are poor and usually mothers are not completing recommended postnatal screening after GDM (Kilgour et al. 2015). The causes of this low compliance are not studied or understood but certainly a quality communication and information is crucial to achieve an effective strategy to complete the recommended postnatal GDM followup. (Kilgour et al. 2015). Furthermore, women should receive education on the long-term risk of type $2 \mathrm{DM}$ and should be encouraged to breastfeed, engage in regular physical activity, and select a highly effective contraceptive method in preparation for subsequent pregnancy (Castorino and Jovanovic 2013).

\section{GDM in low-income countries}

To date, little is known about GDM in low-income countries, particularly in Africa. It is clear that it is essential to find cheap and applicable screening and treatment options.

Prevalence and risk factors of GDM in sub-Saharan Africa seems to be high up to about $14 \%$ and heterogeneous (Mwanri et al. 2015). Interestingly, prevalence of GDM is higher in women with previous stillbirth, family history of type $2 \mathrm{DM}$, and medium upper arm circumference (MUAC) above 28 $\mathrm{cm}$, while women living in rural areas showed sig- nificantly lower prevalence (Anzaku and Musa 2013; Mwanri et al. 2015). In low-income countries, cheaper treatments alternative to insulin are metformin and glibenclamide but authors have suggested as more effective and acceptable strategy a prevention, as an appropriate diet and physical exercise in order to reduce the short- and long-term GDM related complications (Coetzee 2009). More and more studies are necessary to understand this issue and find adequate solutions.

\section{Conclusions}

GDM is a disease with high health and economic costs avoidable or reducible by prevention, screening, and right management (Danyliv et al. 2015). First of all, woman information and education is crucial in order to reach an effective GDM self-management, especially in low-income countries, where therapy resources are limited. In particular, in the Third World, resources should be literacy appropriate with photographs and simple text, including culturally appropriate foods and information. At the same time, new and more research efforts should be done in order to improve knowledge and GDM management. The priority is to standardize diagnosis criteria based on the plasma glucose level and/or other parameters and identified, if possible, the threshold for the pathological hyperglycemia after 24 weeks of gestation. To achieve this goal, it is crucial to even methods such as sample type (serum, plasma or culture supernatant), sample source (maternal, placental, cord), and assay (e.g. enzyme-linked immunosorbent assays, chemiluminescent immunoassay, and radioimmunoassay) and to adjust the results considering major confounders, including maternal age, ethnicity, smoking status, BMI, and glucose levels. Furthermore, it is relevant to clarify and assess the validity and strength of new possible markers, as $25(\mathrm{OH}) \mathrm{D}$, miRNA, inflammatory, and metabolic markers as well as risk factors as PCOS, ART and exposures to $\mathrm{NOx}$ and $\mathrm{SO}_{2}$. Finally, to improve women compliance, it will be necessary to simplify the "patient life" with cost-effective solutions in the medicine care.

\section{References}

Abell SK, De Courten B, Boyle JA, Teede HJ. Inflammatory and Other Biomarkers: Role in Pathophysiology and Prediction of Gestational Diabetes Mellitus. Int J Mol Sci 16, 13442-13473, 2015.

Aktun HL, Uyan D, Yorgunlar B, Acet M. Gestational diabetes mellitus screening and outcomes. J Turk Ger Gynecol Assoc 16, 25-29, 2015. 
Allard C, Sahyouni E, Menard J, Houde G, Pesant MH, Perron P, Ouellet A, Moutquin JM, Ardilouze JL, Hivert MF. Gestational diabetes mellitus identification based on self-monitoring of blood glucose. Can J Diabetes 39, 162-168, 2015.

American Diabetes Association. 2. Classification and Diagnosis of Diabetes. Diabetes Care 39 Suppl 1, S13-S22, 2016. Anzaku AS, Musa J. Prevalence and associated risk factors for gestational diabetes in Jos, North-central, Nigeria. Arch Gynecol Obstet 287, 859-863, 2013.

Aroda VR, Christophi CA, Edelstein SL, Zhang P, Herman WH, Barrett-Connor E, Delahanty LM, Montez MG, Ackermann RT, Zhuo X, Knowler WC, Ratner RE; Diabetes Prevention Program Research Group. The effect of lifestyle intervention and metformin on preventing or delaying diabetes among women with and without gestational diabetes: the Diabetes Prevention Program outcomes study 10-year follow-up. J Clin Endocrinol Metab 100, 1646-1653, 2015.

Artal R. The role of exercise in reducing the risks of gestational diabetes mellitus in obese women. Best Pract Res Clin Obstet Gynaecol 29, 123-132, 2015.

Ashrafi M, Gosili R, Hosseini R, Arabipoor A, Ahmadi J, Chehrazi M. Risk of gestational diabetes mellitus in patients undergoing assisted reproductive techniques. Eur J Obstet Gynecol Reprod Biol 176, 149-152, 2014.

Baz B, Riveline JP, Gautier JF. ENDOCRINOLOGY OF PREGNANCY: Gestational diabetes mellitus: definition, aetiological and clinical aspects. Eur J Endocrinol 174, R43-R51, 2015.

Beharier O, Shoham-Vardi I, Pariente G, Sergienko R, Kessous R, Baumfeld Y, Szaingurten-Solodkin I, Sheiner E. Gestational diabetes mellitus is a significant risk factor for long-term maternal renal disease. J Clin Endocrinol Metab 100, 1412-1416, 2015.

Blue EK, Sheehan BM, Nuss ZV, Boyle FA, Hocutt CM, Gohn CR, Varberg KM, McClintick JN, Haneline LS. Epigenetic Regulation of Placenta-Specific 8 Contributes to Altered Function of Endothelial Colony-Forming Cells Exposed to Intrauterine Gestational Diabetes Mellitus. Diabetes 64, 2664-2675, 2015.

Capula C, Chiefari E, Vero A, Foti DP, Brunetti A, Vero R. Prevalence and predictors of postpartum glucose intolerance in Italian women with gestational diabetes mellitus. Diabetes Res Clin Pract 105, 223-230, 2014.

Castorino K, Jovanovic L. The postpartum management of women with gestational diabetes using a continuum model for health care. Clin Obstet Gynecol 56, 853-859, 2013.

Chu SY, Abe K, Hall LR, Kim SY, Njoroge T, Qin C. Gestational diabetes mellitus: all Asians are not alike. Prev Med 49, 265-268, 2009.

Coetzee EJ. Pregnancy and diabetes scenario around the world: Africa. Int J Gynaecol Obstet 104 Suppl 1, S39-S41, 2009.

Coustan DR. Diagnosis of gestational diabetes. Scand J Clin Lab Invest Suppl. 244, 27-33, discussion 32-33, 2014.

Dall TM, Yang W, Halder P, Pang B, Massoudi M, Wintfeld N, Semilla AP, Franz J, Hogan PF. The economic burden of elevated blood glucose levels in 2012: diagnosed and undiagnosed diabetes, gestational diabetes mellitus, and prediabetes. Diabetes Care 37, 3172-3179, 2014.

Danyliv A, Gillespie P, O’Neill C, Noctor E, O’Dea A, Tierney M, McGuire B, Glynn LG, Dunne F. Short- and longterm effects of gestational diabetes mellitus on healthcare cost: a cross-sectional comparative study in the ATLANTIC DIP cohort. Diabet Med 32, 467-476, 2015.

Eleftheriades M, Papastefanou I, Lambrinoudaki I, Kappou D, Lavranos D, Akalestos A, Souka AP, Pervanidou P, Hassiakos D, Chrousos GP. Elevated placental growth factor concentrations at 11-14 weeks of gestation to predict gestational diabetes mellitus. Metabolism 63, 1419-1425, 2014.

Fadl H, Magnuson A, Ostlund I, Montgomery S, Hanson U, Schwarcz E. Gestational diabetes mellitus and later cardiovascular disease: a Swedish population based case-control study. BJOG 121, 1530-1536, 2014.

Fawole AO, Ezeasor C, Bello FA, Roberts A, Awoyinka BS, Tongo O, Adeleye JO, Ipadeola A. Effectiveness of a structured checklist of risk factors in identifying pregnant women at risk of gestational diabetes mellitus: a crosssectional study. Niger J Clin Pract 17, 495-501, 2014.

Garrison A.Screening, diagnosis, and management ofgestationaldiabetes mellitus. Am Fam Physician 91,460-467,2015.

Girgis CM, Gunton JE, Cheung NW. ISRN Endocrinol 2012, 341638, 2012.

Hashimoto K, Koga M. Indicators of glycemic control in patients with gestational diabetes mellitus and pregnant women with diabetes mellitus. World J Diabetes 6, 1045-1056, 2015.

Hawryluk J, Grafka A, Gęca T, Lopucki M. [Gestational diabetes in the light of current literature]. Pol Merkur Lekarski 38, 344-347, 2015.

Hayase M, Shimada M, Seki H. Sleep quality and stress in women with pregnancy-induced hypertension and gestational diabetes mellitus. Women Birth 27, 190-195, 2014. 
Hernandez TL, Van Pelt RE, Anderson MA, Daniels LJ, West NA, Donahoo WT, Friedman JE, Barbour LA. A higher-complex carbohydrate diet in gestational diabetes mellitus achieves glucose targets and lowers postprandial lipids: a randomized crossover study. Diabetes Care 37, 1254-1262, 2014.

Hinkle SN, Laughon SK, Catov JM, Olsen J, Bech BH. First trimester coffee and tea intake and risk of gestational diabetes mellitus: a study within a national birth cohort. BJOG 122, 420-428, 2015.

Hopmans TE, van Houten C, Kasius A, Kouznetsova OI, Nguyen LA, Rooijmans SV, Voormolen DN, van Vliet EO, Franx A, Koster MP. Increased risk of type II diabetes mellitus and cardiovascular disease after gestational diabetes mellitus: a systematic review. Ned Tijdschr Geneeskd 159, A8043, 2015.

Houshmand A, Jensen DM, Mathiesen ER, Damm P. Evolution of diagnostic criteria for gestational diabetes mellitus. Acta Obstet Gynecol Scand 92, 739-745, 2013.

Issat T, Nowicka MA, Jakimiuk AJ. [Polycystic ovary syndrome (PCOS) and gestational diabetes mellitus (GDM) risk]. Ginekol Pol 86, 392-395, 2015.

Iyidir OT, Degertekin CK, Yilmaz BA, Altinova AE, Toruner FB, Bozkurt N, Ayvaz G, Akturk M. Serum levels of fetuin A are increased in women with gestational diabetes mellitus. Arch Gynecol Obstet 291, 933-937, 2015.

Jiwani A, Marseille E, Lohse N, Damm P, Hod M, Kahn JG. Gestational diabetes mellitus: results from a survey of country prevalence and practices. J Matern Fetal Neonatal Med 25, 600-610, 2012.

Karamanos B, Thanopoulou A, Anastasiou E, Assaad-Khalil S, Albache N, Bachaoui M, Slama CB, El Ghomari H, Jotic A, Lalic N, Lapolla A, Saab C, Marre M, Vassallo J, Savona-Ventura C; MGSD-GDM Study Group. Relation of the Mediterranean diet with the incidence of gestational diabetes. Eur J Clin Nutr 68, 8-13, 2014.

Karamanou M, Protogerou A, Tsoucalas G, Androutsos G, Poulakou-Rebelakou E. Milestones in the history of diabetes mellitus: The main contributors. World J Diabetes 7, 1-7, 2016.

Keskin FE, Ozyazar M, Pala AS, Elmali AD, Yilmaz B, Uygunoglu U, Bozluolcay M, Tuten A, Bingol A, Hatipoglu E. Evaluation of cognitive functions in gestational diabetes mellitus. Exp Clin Endocrinol Diabetes 123, 246-251, 2015.

Khattab S, Mohsen IA, Aboul Foutouh I, Ashmawi HS, Mohsen MN, van Wely M, van der Veen F, Youssef MA. Can metformin reduce the incidence of gestational diabetes mellitus in pregnant women with polycystic ovary syndrome? Prospective cohort study. Gynecol Endocrinol 27, 789-793, 2011.

Kilgour C, Bogossian FE, Callaway L, Gallois C. Postnatal gestational diabetes mellitus follow-up: Australian women's experiences. Women Birth 28, 285-292, 2015.

Kim SY, Saraiva C, Curtis M, Wilson HG, Troyan J, Sharma AJ. Fraction of gestational diabetes mellitus attributable to overweight and obesity by race/ethnicity, California, 2007-2009. Am J Public Health 103, e65-e72, 2013.

Klein P, Polidori D, Twito O, Jaffe A. Impaired decline in renal threshold for glucose during pregnancy - a possible novel mechanism for gestational diabetes mellitus. Diabetes Metab Res Rev 30, 140-145, 2014.

Kwon SS, Kwon JY, Park YW, Kim YH, Lim JB. HbA1c for diagnosis and prognosis of gestational diabetes mellitus. Diabetes Res Clin Pract 110, 38-43, 2015.

Lacroix M, Battista MC, Doyon M, Houde G, Menard J, Ardilouze JL, Hivert MF, Perron P. Lower vitamin D levels at first trimester are associated with higher risk of developing gestational diabetes mellitus. Acta Diabetol 51, 609-616, 2014.

Landon MB, Rice MM, Varner MW, Casey BM, Reddy UM, Wapner RJ, Rouse DJ, Biggio JR Jr, Thorp JM, Chien EK, Saade G, Peaceman AM, Blackwell SC, VanDorsten JP; Eunice Kennedy Shriver National Institute of Child Health and Human Development Maternal-Fetal Medicine Units (MFMU) Network. Mild gestational diabetes mellitus and long-term child health. Diabetes Care 38, 445-452, 2015.

Lappas M. NOD1 expression is increased in the adipose tissue of women with gestational diabetes. J Endocrinol 222, 99-112, 2014.

Lautatzis ME, Goulis DG, Vrontakis M. Efficacy and safety of metformin during pregnancy in women with gestational diabetes mellitus or polycystic ovary syndrome: a systematic review. Metabolism 62, 1522-1534, 2013.

Lewandowski KC, Stojanovic N, Press M, Tuck SM, Szosland K, Bienkiewicz M, Vatish M, Lewinski A, Prelevic GM, Randeva HS. Elevated serum levels of visfatin in gestational diabetes: a comparative study across various degrees of glucose tolerance. Diabetologia 50, 1033-1037, 2007.

Li JW, He SY, Liu P, Luo L, Zhao L, Xiao YB. Association of gestational diabetes mellitus (GDM) with subclinical atherosclerosis: a systemic review and meta-analysis. BMC Cardiovasc Disord 14, 132, 2014.

Liao P, Park AL, Berger H, Ray JG. Using estimated fetal weight from ultrasonography at 18 to 22 weeks to predict gestational diabetes mellitus and newborn macrosomia. J Obstet Gynaecol Can 36, 688-691, 2014. 
Lundberg TP, Hojlund K, Snogdal LS, Jensen DM. Glutamic acid decarboxylase autoantibody-positivity post-partum is associated with impaired $\beta$-cell function in women with gestational diabetes mellitus. Diabet Med 32, 198-205, 2015.

Maged AM, Moety GA, Mostafa WA, Hamed DA. Comparative study between different biomarkers for early prediction of gestational diabetes mellitus. J Matern Fetal Neonatal Med 27, 1108-1112, 2014.

Magon N, Seshiah V. Gestational diabetes mellitus: Non-insulin management. Indian J Endocrinol Metab 15, 284293, 2011.

Maleki N, Tavosi Z. Evaluation of thyroid dysfunction and autoimmunity in gestational diabetes mellitus and its relationship with postpartum thyroiditis. Diabet Med 32, 206-212, 2015.

Mirzamoradi M, Heidar Z, Faalpoor Z, Naeiji Z, Jamali R. Comparison of glyburide and insulin in women with gestational diabetes mellitus and associated perinatal outcome: a randomized clinical trial. Acta Med Iran 53, 97-103, 2015.

Mordwinkin NM, Ouzounian JG, Yedigarova L, Montoro MN, Louie SG, Rodgers KE. Alteration of endothelial function markers in women with gestational diabetes and their fetuses. J Matern Fetal Neonatal Med 26, 507-512, 2013.

Mwanri AW, Kinabo J, Ramaiya K, Feskens EJ. Gestational diabetes mellitus in sub-Saharan Africa: systematic review and metaregression on prevalence and risk factors. Trop Med Int Health 20, 983-1002, 2015.

Olesen CR, Nielsen JH, Mortensen RN, Boggild H, Torp-Pedersen C, Overgaard C. Associations between followup screening after gestational diabetes and early detection of diabetes--a register based study. BMC Public Health 14, 841, 2014.

Oliveira AP, Calderon IM, Costa RA, Roscani MG, Magalhaes CG, Borges VT. Assessment of structural cardiac abnormalities and diastolic function in women with gestational diabetes mellitus. Diab Vasc Dis Res 12, 175-180, 2015.

Padayachee C, Coombes JS. Exercise guidelines for gestational diabetes mellitus. World J Diabetes 6, 1033-1044, 2015.

Pala HG, Ozalp Y, Yener AS, Gerceklioglu G, Uysal S, Onvural A. Adiponectin levels in gestational diabetes mellitus and in pregnant women without glucose intolerance. Adv Clin Exp Med 24, 85-92, 2015.

Poomalar GK, Rangaswamy V. A comparison of fasting plasma glucose and glucose challenge test for screening of gestational diabetes mellitus. J Obstet Gynaecol 33, 447-450, 2013.

Poomalar GK. Changing trends in management of gestational diabetes mellitus. World J Diabetes 6, 284-295, 2015.

Qiu C, Williams MA, Vadachkoria S, Frederick IO, Luthy DA. Increased maternal plasma leptin in early pregnancy and risk of gestational diabetes mellitus. Obstet Gynecol 103, 519-525, 2004.

Rahimi G, Jafari N, Khodabakhsh M, Shirzad Z, Dogaheh HP. Upregulation of microRNA processing enzymes Drosha and Dicer in gestational diabetes mellitus. Gynecol Endocrinol 31, 156-159, 2015.

Reyes-Lopez R, Perez-Luque E, Malacara JM. Metabolic, hormonal characteristics and genetic variants of TCF7L2 associated with development of gestational diabetes mellitus in Mexican women. Diabetes Metab Res Rev 30, 701-706, 2014.

Robledo CA, Mendola P, Yeung E, Mannisto T, Sundaram R, Liu D, Ying Q, Sherman S, Grantz KL. Preconception and early pregnancy air pollution exposures and risk of gestational diabetes mellitus. Environ Res 137, 316-322, 2015.

Roca-Rodriguez MM, Lopez-Tinoco C, Murri M, Fernandez-Deudero A, Garcia-Palacios MV, Garcia-Valero MA, Tinahones-Madueno FJ, Aguilar-Diosdado M. Postpartum development of endothelial dysfunction and oxidative stress markers in women with previous gestational diabetes mellitus. J Endocrinol Invest 37, 503-509, 2014.

Ruchat SM, Mottola MF. The important role of physical activity in the prevention and management of gestational diabetes mellitus. Diabetes Metab Res Rev 29, 334-346, 2013.

Ryu RJ, Hays KE, Hebert MF. Gestational diabetes mellitus management with oral hypoglycemic agents. Semin Perinatol 38, 508-515, 2014.

Sanabria-Martinez G, Garcia-Hermoso A, Poyatos-Leon R, Alvarez-Bueno C, Sanchez-Lopez M, Martinez-Vizcaino V. Effectiveness of physical activity interventions on preventing gestational diabetes mellitus and excessive maternal weight gain: a meta-analysis. BJOG 122, 1167-1174, 2015.

Schwartz ML, Ray WN, Lubarsky SL. The diagnosis and classification of gestational diabetes mellitus: is it time to change our tune? Am J Obstet Gynecol 180, 1560-1571, 1999.

Shapiro GD, Dodds L, Arbuckle TE, Ashley-Martin J, Fraser W, Fisher M, Taback S, Keely E, Bouchard MF, Monnier P, Dallaire R, Morisset A, Ettinger AS. Exposure to phthalates, bisphenol A and metals in pregnancy and the association with impaired glucose tolerance and gestational diabetes mellitus: The MIREC study. Environ Int 83, 63-71, 2015. 
Shuang W, Huixia Y. [Analysis of the effect of risk factors at gestational diabetes mellitus]. Zhonghua Fu Chan Ke Za Zhi 49, 321-324, 2014.

Simmons D. Safety considerations with pharmacological treatment of gestational diabetes mellitus. Drug Saf 38, 65-78, 2015.

Sobrevia L, Salsoso R, Saez T, Sanhueza C, Pardo F, Leiva A. Insulin therapy and fetoplacental vascular function in gestational diabetes mellitus. Exp Physiol 100, 231-238, 2015.

Tarquini F, Picchiassi E, Centra M, Pennacchi L, Bini V, Cappuccini B, Torlone E, Coata G, Di Renzo G, Brancorsini S. Body mass index associated to rs2021966 ENPP1 polymorphism increases the risk for gestational diabetes mellitus. Gynecol Endocrinol 31, 83-86, 2015.

Twedt R, Bradley M, Deiseroth D, Althouse A, Facco F. Sleep Duration and BloodGlucose Control in Women With Gestational Diabetes Mellitus. Obstet Gynecol 126, 326-331, 2015.

Vambergue A. [Gestational diabetes: diagnosis, short and long term management]. Presse Med 42, 893-899, 2013.

Yeral MI, Ozgu-Erdinc AS, Uygur D, Seckin KD, Karsli MF, Danisman AN. Prediction of gestational diabetes mellitus in the first trimester, comparison of fasting plasma glucose, two-step and one-step methods: a prospective randomized controlled trial. Endocrine 46, 512-518, 2014.

Yuen L, Wong VW. Gestational diabetes mellitus: Challenges for different ethnic groups. World J Diabetes 6, 10241032, 2015.

Zhu Y, Tian F, Li H, Zhou Y, Lu J, Ge Q. Profiling maternal plasma microRNA expression in early pregnancy to predict gestational diabetes mellitus. Int J Gynaecol Obstet 130, 49-53, 2015. 